\title{
Profil Massa Lemak dan Lingkar Pinggang Dewasa Obes dan Nonobes di Cirebon
}

\author{
Stephanus Kristianto Witono, ${ }^{1}$ Gaga Irawan Nugraha, ${ }^{2}$ Hikmat Permana, ${ }^{3}$ Sudigdo Adi $^{4}$ \\ ${ }^{1}$ Program Studi Magister Anti-aging dan Aesthetic Medicine, ${ }^{2}$ Departemen Ilmu Gizi, \\ 3Departemen Ilmu Penyakit Dalam, ${ }^{4}$ Departemen Ilmu Kesehatan Kulit dan Kelamin, \\ Fakultas Kedokteran, Universitas Padjadjaran, Bandung, Indonesia
}

\begin{abstract}
Abstrak
Kelebihan berat badan dan kegemukan mulai menjadi masalah terhadap kesehatan pada beberapa dekade terakhir. Hal ini menjadi masalah serius terhadap kesehatan karena dapat menyebabkan sindrom metabolik yang berujung kepada kematian sehingga kegemukan perlu kita cegah sedini-dininya. Deteksi dini khususnya massa lemak dan lingkar pinggang yang menjadikan faktor prediktor sindrom metabolik perlu dilakukan untuk mencegah perjalanan penyakit obesitas. Penelitian deskriptif ini dilakukan terhadap 116 subjek (47 subjek obes dan 69 nonobes) di Klinik Pasar Balong Cirebon, 14-21 April 2016 dengan rentang usia 35-60 tahun. Pengukuran berat badan, massa lemak, dan massa bebas lemak menggunakan professional octapolar body impedance analyzer Beurer BF1oo, pengukuran tinggi badan menggunakan Stadiometer Seca 213 dan lingkar pinggang menggunakan body tape measure caliper Onemed. Tujuan penelitian ini adalah mengetahui persentase massa lemak dan lingkar pinggang dewasa obes dengan nonobes di Kota Cirebon sehingga dapat dijadikan acuan dalam mengatasi obesitas. Hasil massa lemak rata-rata pria dan wanita obes $30,98 \pm 4,24 \%$ dan $39,29 \pm 3,56 \%$, serta lingkar pinggang 108,20 $\pm 7,59 \mathrm{~cm}$ dan $93,46 \pm 8,91 \mathrm{~cm}$ yang berarti rata-rata dewasa obes di Cirebon mempunyai massa lemak jauh di atas klasisfikasi buruk dari American College of Sport Medicine dan lingkar pinggang jauh di atas batasan WHO dan International Diabetes Federation untuk orang Asia. Hasil massa lemak rata-rata pria nonobes dalam klasifikasi rata-rata $17,81 \pm 5,21 \%$ dan wanita

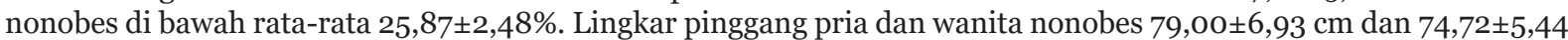
$\mathrm{cm}$, masih dalam klasifikasi normal. Simpulan, orang dewasa di Kota Cirebon baik obes maupun nonobes khususnya wanita mempunyai massa lemak masuk ke dalam klasifikasi buruk. Lingkar pinggang dewasa obes baik pria maupun wanita melebihi batasan WHO dan International Diabetes Federation.
\end{abstract}

Kata kunci: Dewasa, Kota Cirebon, lingkar pinggang, massa lemak, nonobes, obes

\section{Fat Mass and Waist Circumference Profile of Adult Obese and Non-Obese in Cirebon}

\begin{abstract}
Overweight and obesity are starting to become a serious health problems in the last few decades because it can cause metabolic syndrome that leads to death, so we need to prevent obesity as early as possible. We need to do early detection especially fat mass percentage and waist circumference that makes predictor factor of the occurrence of metabolic syndrome is needed to prevent or even to cut the course of obesity disease. This descriptive study was conducted on 116 patients (47 obese and 69 non-obese patients) at the Klinik Pasar Balong Cirebon, April 14-21, 2016 with age range of $35-60$ years. Measurement of body weight, fat mass, fat free mass using professional octapolar body impedance analyzer Beurer BF100, while height measurement using Seca 213 Stadiometer and waist circumference using body tape measure caliper Onemed. The purpose of this research was to know fat mass and waist circumference of obese and non-obese in Cirebon, so it can be used as a reference in overcoming obesity. The mean value of fat mass men and women obese were $30.98 \pm 4.24 \%$ and $39.29 \pm 3.56 \%$, and waist circumference $108.20 \pm 7.59 \mathrm{~cm}$ and $93.46 \pm 8.91 \mathrm{~cm}$, which means the mean value obese adults in Cirebon had fat mass far above the bad classification of American College of Sport Medicine and waist circumference far above the boundaries of the WHO and International Diabetes Federation for Asians. The mean value of non-obese fat mass percentage gain in the average classification was $17.81 \pm 5.21 \%$ and non-obese women in the classification below the average $25.87 \pm 2.48 \%$. Non-obese male and female waist circumference $79.00 \pm 6.93 \mathrm{~cm}$ and $74.72 \pm 5.44 \mathrm{~cm}$, still in normal classification. In conclusion, adults in Cirebon both obese and non-obese, especially women have fat mass percentage fall into bad classification. While obese adult waist circumference exceeds the limits of WHO and International Diabetes Federation.
\end{abstract}

Key words: Adult, Cirebon, fat mass, non-obese, obese, waist circumference

Received: 14 January 2017; Revised: 9 March 2018; Accepted: 9 April 2018; Published: 30 April 2018

Korespondensi: Stephanus Kristianto Witono. Program Studi Magister Anti-aging dan Aesthetic Medicine, Fakultas Kedokteran, Universitas Padjadjaran. Jln. Prof. Dr. Eyckman No. 38, Bandung 40161, Jawa Barat, Indonesia. Telepon: (022) 2032170. Surel: psbalong@yahoo.com 


\section{Pendahuluan}

Kelebihan berat badan dan kegemukan mulai menjadi masalah yang serius terhadap kesehatan pada beberapa dekade yang terakhir. Pada tahun 2010, kegemukan diperkirakan mengakibatkan 3,4 juta kematian di seluruh dunia. ${ }^{1}$ Pada tahun 2016, lebih dari 1,9 miliar orang (terdiri atas 39\% pria dan $40 \%$ wanita) dewasa berusia 18 tahun ke atas mengalami kelebihan berat badan. Secara keseluruhan, sekitar $13 \%$ populasi orang dewasa di dunia ( $11 \%$ pria dan $15 \%$ wanita) mengalami obesitas. Prevalensi obesitas di seluruh dunia baik di negara barat maupun di Asia tahun 1975 dan 2016 meningkat hampir tiga kali lipat. ${ }^{2-4}$

Metode yang paling banyak digunakan untuk mengukur tingkat obesitas adalah indeks massa tubuh (IMT). Berat badan lebih atau overweight dengan IMT di atas $25 \mathrm{~kg} / \mathrm{m}^{2}$ mencapai $50-70 \%$, terdapat di sebagian besar negara berkembang yang ternyata berdampak terhadap peningkatan terjadinya risiko sindrom metabolik., ${ }^{1,2,4}$ Selain IMT, metode penentuan komposisi tubuh yang terdiri atas massa lemak dan massa bebas lemak memiliki tingkat akurasi tinggi untuk mengetahui peningkatan risiko sindrom metabolik. ${ }^{5}$

Peningkatan prevalensi kegemukan di dunia serta efek samping kegemukan itu memerlukan peningkatan pengawasan perubahan prevalensi kelebihan berat badan dan juga kegemukan pada semua populasi. Risiko gangguan kesehatan yang meningkat (kegemukan) merupakan tantangan utama kesehatan global. ${ }^{2}$ Sejalan dengan itu maka sangat penting bagi para pembuat keputusan untuk memprioritaskan tindakan pencegahan. ${ }^{5}$

Perubahan gaya hidup di negara kita Indonesia yang menjurus kepada westernisasi khususnya yang terjadi di kota-kota besar, berakibat pada perubahan pola hidup terutama pola makan atau konsumsi yang merujuk pada pola makan tinggi energi, lemak, dan kolesterol. Hal ini tampak terutama pada makanan siap saji (fast food) yang berdampak meningkatkan risiko obesitas. ${ }^{6}$

Sebagian besar kegemukan disebabkan oleh interaksi antara faktor sosioekonomi dan nutrisi, yaitu perilaku makan dan pemberian makanan padat yang terlalu dini pada bayi. ${ }^{7}$ Perubahan pola makan pada orang dewasa dan aktivitas tubuh yang kurang dalam kehidupan sehari-hari sangat menentukan penimbunan lemak di dalam tubuh sehingga menyebabkan kegemukan dan meningkatkan risiko sindrom metabolik serta beberapa tipe kanker.3,4,8
Hasil laporan Riset Kesehatan Dasar 2013 menyatakan obesitas umum pada orang dewasa (usia lebih dari 18 tahun) 15,4\%.9 Obesitas pria dewasa (lebih dari 18 tahun) 19,7\%, lebih tinggi dibanding dengan tahun 2010 (13,9\%). Obesitas perempuan dewasa (lebih dari 18 tahun) tahun $2013(32,9 \%)$ lebih tinggi daripada tahun 2010 (15,5\%). ${ }^{9}$ Bila dilihat secara nasional, obesitas sentral dewasa (lingkar pinggang pria lebih dari $90 \mathrm{~cm}$ dan perempuan lebih dari $80 \mathrm{~cm}),{ }^{4} 26,6 \%$ lebih tinggi daripada tahun 2007 (18,8\%). ${ }^{9}$ Hasil pelaporan dari Survei Sosial Ekonomi Nasional (Susenas) tahun 2009, prevalensi obesitas pada balita mengalami peningkatan baik di perkotaan maupun pedesaan. ${ }^{10}$

Tingkat sosial ekonomi seseorang merupakan keadaan orang tersebut dilihat dari pendidikan, penghasilan, dan juga status pekerjaan. Kelas sosial dan status sosial ekonomi memengaruhi prevalensi obesitas.7 Seiring dengan perubahan tingkat sosial ekonomi masyarakat Kota Cirebon maka terjadi pergeseran pola hidup sehingga banyak masyarakat Kota Cirebon yang terpapar obesitas. ${ }^{11}$ Mengingat dampak timbunan lemak dan juga lingkar pinggang yang merujuk pada sindrom metabolik itu maka perlu dilaksanakan penelitian terhadap persentasi massa lemak dan lingkar pinggang pada dewasa obes dan nonobes di Kota Cirebon perlu dilakukan. ${ }^{11}$ Penelitian ini bertujuan mengetahui persentasi massa lemak dan lingkar pinggang dewasa obes dan nonobes di Kota Cirebon sehingga dapat menjadi landasan untuk membuat keputusan yang tepat untuk pencegahan obesitas di Kota Cirebon.

\section{Metode}

Sampel dipilih dari subjek yang berkunjung ke Klinik Pasar Balong Cirebon pada tanggal 14-21 April 2016 dengan rentang usia 35-60 tahun.

Pengukuran terhadap berat badan, massa lemak, dan massa bebas lemak dilakukan dengan alat ukur professional octapolar body impedance analyzer Beurer BF 100 dengan syarat tidak berolahraga dalam 24 jam terakhir, pemeriksaan dilaksanakan sesudah subjek buang air kecil (BAK) maksimal 30 menit sebelum dilakukan pemeriksaan dan minum air setidaknya 30 menit sebelum pemeriksaan, dan tidak menggunakan diuretik dalam 7 hari terakhir. Pengukuran tinggi badan mempergunakan stadiometer Seca 213 dengan berdiri di atas stadiometer tanpa alas kaki, berdiri tegak dengan posisi kepala memandang 
lurus ke depan, kaki rapat, belikat, pinggul serta bahu menempel pada alat ukur itu. Pengukuran lingkar pinggang dengan mengangkat pakaian yang menutupi daerah pinggang itu. Gunakan jari untuk dapat menemukan bagian atas pinggul dan pangkal tulang rusuk. Ditentukan daerah tersempit di antara dua bagian tulang ini dan berdiri tegak serta mengeluarkan napas perlahan. Ujung body tape measure caliper Onemed yang diletakkan di pusar dipegang dan lingkarkan ke sekeliling pinggang. Posisi body tape measure caliper harus sejajar dengan lantai dan pas di sekitar badan tanpa masuk ke dalam kulit.

Penentuan obes didasarkan atas indeks massa tubuh yang menggambarkan kelebihan jaringan lemak di seluruh tubuh yang dapat dihitung dengan membagi berat badan dalam kilogram (kg) dengan tinggi badan dalam meter pangkat dua $\left(\mathrm{m}^{2}\right)$.

$\mathrm{IMT}=\mathrm{BB}(\mathrm{kg}) / \mathrm{TB}\left(\mathrm{m}^{2}\right)$.

Kriteria obesitas berdasar atas batasan yang ditetapkan oleh WHO untuk negara AsiaPasifik. ${ }^{14}$ Orang normal dengan IMT berkisar $18,5-22,9 \mathrm{~kg} / \mathrm{m}^{2}$, sedangkan IMT $23,0-24,9 \mathrm{~kg} /$ $\mathrm{m}^{2}$ adalah termasuk berisiko, dan orang obes bila IMT di atas $25,0 \mathrm{~kg} / \mathrm{m}^{2}$.

Kriteria yang telah ditetapkan oleh American College of Sport Medicine (ACSM) ${ }^{13}$ untuk orang dewasa dengan persentase massa lemak pada pria 13,9-17,4\% dan wanita $18-21,5 \%$. Persentase massa lemak rata-rata pada pria $17,5-20,4 \%$ dan wanita 21,6-24,8\%. Persentase massa lemak di bawah rata-rata pada pria $20,5-24,1 \%$ dan wanita $24,9-29,2 \%$. Dewasa dengan persentase massa lemak buruk pada pria $>22,4 \%$ dan wanita $>29,3 \%$.

Kriteria lingkar pinggang mengikuti batasan yang telah ditetapkan $\mathrm{WHO}^{14}$ dan International Diabetes Federation (IDF) ${ }^{15,16}$ khusus untuk orang Asia adalah pria $<90 \mathrm{~cm}$ dan wanita $<80$ $\mathrm{cm}$.

Persetujuan etik penelitian (etichal clearance) didapat dari Komisi Etik Penelitian Kesehatan, Fakultas Kedokteran, Universitas Padjadjaran Bandung melalui surat Nomor: 222/UN6.C10/ $\mathrm{PN} / 2017$.

\section{Hasil}

Sesuai dengan kriteria yang ditetapkan oleh ACSM, ${ }^{13}$ hasil pemeriksaan dewasa obes baik pria maupun wanita mempunyai massa lemak yang masuk ke dalam kategori buruk. Hal ini menunjukkan dewasa obes baik pria maupun wanita mempunyai persentase massa lemak yang jauh di atas rata-rata, sedangkan dewasa obes baik pria maupun wanita mempunyai lingkar pinggang jauh di atas batasan WHO dan IDF. ${ }^{14-}$ ${ }^{16} \mathrm{Hal}$ ini menunjukkan risiko terjadi sindrom metabolik sangat tinggi.

Sesuai dengan kriteria yang ditetapkan oleh ACSM,${ }^{13}$ hasil pemeriksaan dewasa pria nonobes mempunyai persentase massa lemak yang masuk ke dalam kategori rata-rata, sedangkan wanita nonobes mempunyai persentase massa lemak yang masuk ke dalam kategori di bawah rata-rata. Hal ini memperlihatkan dewasa wanita nonobes mempunyai presentasi massa lemak yang lebih tinggi daripada nilai rata-rata, sedangkan lingkar pinggang dewasa nonobes baik pada pria maupun wanita tidak melebihi batasan yang ditetapkan oleh WHO dan IDF. ${ }^{14-16}$

\section{Pembahasan}

Penelitian deskriptif ini dilaksanakan 14-21 April 2016 terhadap subjek rawat jalan di Klinik Pasar Balong terhadap 116 orang subjek penelitian (47 subjek obes dan 69 nonobes) yang berusia $35-60$ tahun secara acak.

\section{Tabel 1 Karakteristik Dewasa Obes}

\begin{tabular}{lcc}
\hline Karakteristik & $\begin{array}{c}\text { Rata-rata Pria } \\
\mathbf{n = 2 0}(\mathbf{4 3 \% )}\end{array}$ & $\begin{array}{c}\text { Rata-rata Wanita } \\
\text { n=27 (57\%) }\end{array}$ \\
\hline Tinggi badan $(\mathrm{cm})$ & $170,35 \pm 5,40$ & $156,00 \pm 5,08$ \\
Berat badan $(\mathrm{kg})$ & $97,09 \pm 11,24$ & $78,15 \pm 10,28$ \\
IMT $\left(\mathrm{kg} / \mathrm{m}^{2}\right)$ & $33,58 \pm 4,15$ & $32,61 \pm 3,93$ \\
Massa lemak (\%) & $30,98 \pm 4,24$ & $39,29 \pm 3,56$ \\
Massa bebas lemak (\%) & $69,55 \pm 4,89$ & $62,67 \pm 3,72$ \\
Lingkar pinggang $(\mathrm{cm})$ & $108,20 \pm 7,59$ & $93,46 \pm 8,91$ \\
\hline
\end{tabular}


Tabel 2 Karakteristik Dewasa Nonobes

\begin{tabular}{|c|c|c|}
\hline Karakteristik & $\begin{array}{c}\text { Rata-rata Pria } \\
n=33(48 \%)\end{array}$ & $\begin{array}{c}\text { Rata-rata Wanita } \\
n=36(52 \%)\end{array}$ \\
\hline Tinggi badan $(\mathrm{cm})$ & $165,00 \pm 5,74$ & $154,39 \pm 5,72$ \\
\hline Berat badan (kg) & $56,08 \pm 3,62$ & $51,43 \pm 5,07$ \\
\hline $\operatorname{IMT}\left(\mathrm{kg} / \mathrm{m}^{2}\right)$ & $22,03 \pm 2,11$ & $21,55 \pm 1,35$ \\
\hline Massa lemak (\%) & $17,81 \pm 5,21$ & $25,87 \pm 2,48$ \\
\hline Massa bebas lemak (\%) & $82,19 \pm 5,21$ & $74,15 \pm 2,55$ \\
\hline Lingkar pinggang $(\mathrm{cm})$ & $79,00 \pm 6,93$ & $74,72 \pm 5,44$ \\
\hline
\end{tabular}

Persentase dari massa lemak tubuh rata-rata penduduk dewasa obes Kota Cirebon ternyata jauh di atas klasifikasi buruk yang ditetapkan oleh ACSM (pada pria 30,98 $\pm 4,24 \%$ dan wanita $39,29 \pm 3,56 \%)$. Lingkar pinggang dewasa obes Kota Cirebon (pria 108,20 $\pm 7,59 \mathrm{~cm}$ dan wanita $93,46 \pm 8,91 \mathrm{~cm}$ ) juga jauh lebih besar daripada batasan yang ditetapkan oleh WHO dan IDF.1416 Presentase massa lemak rata-rata dewasa

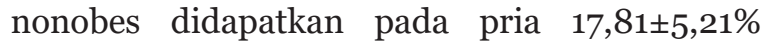
yang termasuk dalam klasifikasi rata-rata ACSM dan wanita nonobes dalam klasifikasi di bawah

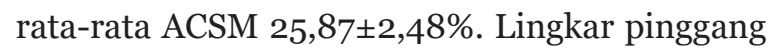
dewasa pria nonobes $79,00 \pm 6,93 \mathrm{~cm}$ yang berarti hampir melebihi batasan yang ditetapkan oleh WHO dan IDF, sedangkan wanita 74,72+5,44 cm yang berarti masih dalam batasan normal WHO dan IDF. ${ }^{14-16}$ Persentasi massa lemak rata-rata pria baik obes maupun nonobes lebih rendah jika dibanding dengan wanita. Hal ini dimungkinkan karena sebagian besar pencari nafkah keluarga di Kota Cirebon adalah kaum pria sehingga kaum pria lebih aktif dibanding dengan kaum wanita. Penggunaan energi dipastikan lebih tinggi pada kaum pria.

Hasil penelitian tersebut di atas membuktikan bahwa hampir semua penduduk di Kota Cirebon memiliki kelebihan asupan energi tanpa diikuti dengan pengeluaran energi yang signifikan. Hal ini terjadi pada kelompok dewasa obes maupun nonobes. Dapat dilihat dari makanan-makanan favorit di Kota Cirebon yang sangat kaya dengan karbohidrat simpel dan lemak akan membuat masukan energi pada masyarakat Kota Cirebon menjadi lebih tinggi daripada kebutuhan yang tentu saja memicu kelebihan berat badan bahkan obes.

Penelitian yang dilakukan Jafar ${ }^{6}$ menyatakan bahwa pemilihan makanan terkait dengan tingkat sosial-ekonomi ternyata tidak terbukti untuk masyarakat di Kota Cirebon. Produk domestik regional bruto (PDRB) Kota Cirebon pada tahun 2015 sebesar Rp4.527.000,00 ${ }^{11}$ jauh melebihi PDB Indonesia Rp3.766.000,00 ${ }^{14}$ ternyata tidak membuat pilihan makanan di Cirebon berubah. Hal ini dimungkinkan karena untuk mengubah kebiasaan pilihan makanan diperlukan waktu cukup lama.

Penelitian yang dilakukan $\mathrm{Ng}$ dkk. ${ }^{5}$ serta Anwar ${ }^{7}$ membuktikan bahwa kebiasaan pilihan jenis makanan dan asupan energi pada usia anakanak juga menyebabkan kegemukan. Hampir semua penjual makanan yang berada di taman kanak-kanak dan sekolah-sekolah dasar hanya menjual makanan yang kaya energi terbuat dari karbohidrat simpel dan lemak jenuh. Keadaan ini menyebabkan perubahan gen yang memicu kegemukan di usia dewasa.

Walaupun demikian, penelitian deskriptif ini hanya mengambil sampel dari populasi subjek dewasa baik obes maupun nonobes yang berobat di Klinik Pasar Balong.

\section{Simpulan}

Dari hasil pemeriksaan persentase massa lemak serta lingkar pinggang pria dan wanita dewasa obes dan nonobes di Kota Cirebon ternyata jauh melebihi batasan dari ACSM serta WHO dan IDF untuk orang Asia, bahkan persentase massa lemak dewasa nonobes juga melebihi batasan yang seharusnya. Hal ini dapat diartikan bahwa asupan energi dewasa obes dan nonobes di Kota Cirebon jauh melebihi kebutuhan energi yang diperlukan.

\section{Daftar Pustaka}

1. World Health Organization. Global Health Observatory (GHO) data. Obesity: situation 
and trends [diunduh 27 April 2015]. Tersedia dari: http://www.who.int/gho/ncd/risk_ factors/obesity_text/en/.

2. World Health Organization. Obesity and overweight fact sheet [diunduh 27 April 2015]. Tersedia dari: http://www.who.int/ mediacentre/factsheets/fs311/en/.

3. Hossain P, Kawar B, El Nahas M. Obesity and diabetes in the developing world-a growing challenge. N Engl J Med. 2007;356:213-5.

4. International Obesity Task Force. The AsiaPacific perspective: redefining obesity and its treatment. Melbourne: World Health Organization-Western Pacific Region; 2000.

5. Ng M, Fleming T, Robinson M, Thomson B, Graetz N, Margono C, dkk. Global, regional, and national prevalence of overweight and obesity in children and adults during 19802013: a systematic analysis for the Global Burden of Disease Study 2013. Lancet. 2014;384(9945):766-81.

6. Jafar N. Analisis pola makanan dan aktivitas terhadap sindroma metabolik pada berbagai tingkat sosial ekonomi. Litbangkes DepKes RI. [diunduh 28 April 2015]. Tersedia dari: http://grey.litbang.depkes.go.id/gdl.php?m od=browse\&op=read\&id=jkpkbppk-gdl-res2009-researches-3202\&q=obesitas.

7. Anwar S. Obesitas dalam masyarakat. Dalam: Yudhistira A, penyunting. Obesitas. Surabaya: Pariwara; 2008. hlm. 58-9.

8. Zietek T, Rath E. Inflammation meets metabolic disease: gut feeling mediated by GLP-1. Front Immunol. 2016;7:154.

9. Badan Litbang Kesehatan, Kementerian Kesehatan Republik Indonesia. Riset kesehatan dasar (Riskesdas) 2013. Jakarta: Badan Litbang Kesehatan, Kemenkes RI; 2013.
10. Badan Pusat Statistik. Survei sosial ekonomi nasional (Susenas) kor, 2009 [diunduh 28 April 2015]. Tersedia dari: https:// sirusa.bps.go.id/sirusa/index.php/dasar/ pdf?kd=1558\&th=2009.

11. Badan Pusat Statistik Kota Cirebon. Produk domestik regional bruto menurut lapangan usaha 2010-2015 [diunduh 21 April 2015]. Tersedia dari: http://bappeda.cirebonkota. go.id/wp-content/uploads/2016/12/PDRBKota-Cirebon-2011-2015.pdf.

12. Badan Pusat Statistik Indonesia. Pendapatan nasional Indonesia 2011-2015. Jakarta: Badan Pusat Statistik Indonesia; 2016.

13. Dwyer GB, Davis SE. ACSM's healthrelated physical fitness assessment manual. Baltimore: Lippincott Williams \& Wilkins; 2008.

14. World Health Organization. Waist circumference and waist-hip ratio. Report of a WHO Expert Consultation. Geneva; 8-11 December 2008. Geneva: WHO Press; 2011.

15. National Institute for Health and Clinical Excellence. Public health draft guidance. Assessing body mass index and waist circumference thresholds for intervening to prevent ill health and premature death among adults from black, Asian and other minority ethnic groups in the UK [diunduh 21 April 2015]. Tersedia dari: https://www. nice.org.uk/guidance/ph46/documents/ bmi-and-waist-circumference-black-andminority-ethnic-groups-draft-guidance2.

16. Pratyush DD, Tiwari S, Singh S, Singh SK. Waist circumference cutoff and its importance for diagnosis of metabolic syndrome in Asian Indians: a preliminary study. Indian J Endocrinol Metab. 2012;16(1):112-5. 